\title{
Exploration and Practice of the Dynamic Cultivation Process of the Core Values of Contemporary Chinese Revolutionary Soldiers
}

\section{Q. H. Song 1 , 2*}

${ }^{\mathbf{1}}$ Army Logistics Academy, Chongqing Key Laboratory of Geomechanics \& Geoenvironment Protection, 401331 Chongqing, China

${ }^{2}$ Technology Innovation Centre of Geohazards Automatic Monitoring, Ministry of Nature Resources (Chongqing Institute of Geology \& Mineral Resources), 401120 Chongqing,

\section{China}

DOI - http://doi.org/10.37502/IJSMR.2021.4605

\begin{abstract}
The professional characteristics of Chinese revolutionary soldiers determine that they are always facing various risks and challenges full of uncertainty and complexity. In order to effectively deal with various risks and challenges, it is urgent for every Chinese soldier to have the quality and ability to "Follow the Party, fight to win and forge exemplary conduct", which is based on the core values of soldiers in the final analysis. However, the formation of core values is not achieved overnight, but a complex process of dynamic improvement with personal growth and progress, the ability to perform their duties and the ability to learn, reflect and summarize. By means of case analysis and the combination of induction and deduction, combined with the change of responsibility and mission in the process of personal post transformation, the author focuses on the direction and principles that should be grasped in the formation of personal values, as well as the relationship between personal values and the combination and inheritance of contemporary military core values. The results show that the formation process of Chinese soldiers' core values has a solid foundation, strong plasticity, practicality, effectiveness and sustainability, and the core values are the strong cornerstone for Chinese soldiers to deal with all risks and challenges.
\end{abstract}

Keywords: Core values; Chinese revolutionary soldiers; dynamic cultivation process.

\section{Introduction}

What is value? What are values? What are the core values of Chinese revolutionary soldiers?

As a Chinese soldier, what kind of value should he pursue? How to form personal values? A series of questions about value orientation often trigger my thinking.

From the perspective of value philosophy, value is a kind of relation category, which refers to the relationship between satisfaction and being satisfied formed in the process of people's understanding and transforming the world. In short, it is what a person can do and what he can do. And the value of putting aside the concept of philosophy, of course, is the inner thought of doing everything, the principle and criterion of doing things. 
In recent years, most of the theoretical research (Chen, 2015; Dong \& Zhou, 2014; Du, 2014; Fang, 2016; Liu \& Zhang, 2015; Liu, 2017; Ma, 2014; Song, 2015; Sui, 2014; Tan, 2016; Wang \& Zhang, 2018; Wang, 2018; Xu, 2016) on the core values of contemporary Chinese soldiers is based on the macro-level ideological and political theory. For example, the U.S. military attaches great importance to the construction of military core values, and designated 1986 as the "Year of military values" (Wang, 2018). This paper explores the core values of contemporary Chinese soldiers from a new perspective of the dynamic development process of the gradual formation and constant revision of the values in the process of personal growth. In this paper, the author will combine the ideological changes of three roles in the process of personal transformation from a cadet to a teacher and then to a team leader, and focus on discussing the direction and principles that should be grasped in the formation of personal values, as well as the relationship between the combination and inheritance of personal values and the core values of contemporary soldiers.

\section{Role Change and Core Value Invariance -- Realistic Perception of the Guidance of Core Values}

As an "old person of LEU (Logistical Engineering University), I had completed this major change from being an ordinary person to a professional soldier in the process of studying for 11 consecutive years since I entered the school in 1999. After graduation of Ph.D., I was lucky to stay in my alma mater and continue to work. I have the opportunity to devote my hands to the construction and development of the alma mater. I got used to my role as a student and became a faculty member for the first time in July 2010. In September 2011, following the organization's arrangement and becoming a student team leader, the team leader once again entered the life of the students and changed for the second time. The roles seem to be completely different, but they are essentially related. Under the strong leadership of the Party committee the academy, the grass-roots level of our hospital includes three parts (as shown in Fig. 1). They are the three identities I have just experienced: student, teacher and team leader. The three basic levels under the leadership of the agency are responsible for cultivating outstanding logistics personnel, organizing scientific, teach research and practice and other key tasks. The unsteady ground at the grassroots level is swaying. Grassroots instability of the ground shaking, only based on a strong grass-roots organization, the overall development and progress of the future workers can achieve a target. Only by recognizing this basic reality can we deal with the relationship between individuals and collectives.

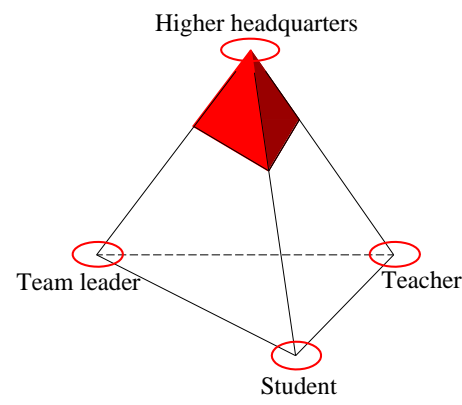

(a)

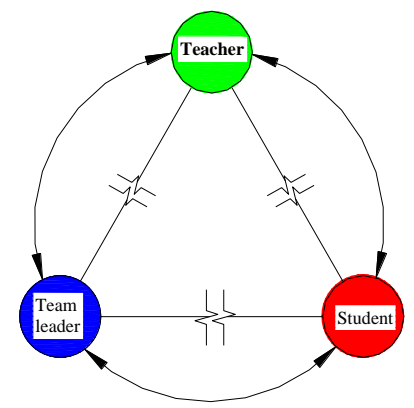

(b)

Fig.1: The Relationship Model of Three Grass-roots and Superior Organs (a) Relationship between higher authorities and three grass-roots units; (b) Model of three grass-roots relations 
What cannot be ignored is that due to the constraints of various objective factors, there are still many problems in the mutual communication and cooperation among these three grass-roots units, such as sometimes the teachers do not know what the students think, the team leaders cannot catch students' thought, the communication between the teachers and the team leaders is not enough, and the students cannot understand the good intentions of the team leaders. All kinds of problems restrict the cultivation and development of talents to some extent. How to strengthen the coordination and cooperation between the three basic levels has become a key issue that needs to be solved urgently in the construction of college education and talent training.

The theme of "what changes is identity and what remains unchanged is values" will be discussed in the following paragraphs, in combination with personal experiences and thoughts that fluctuate in different roles. In the process of identity transformation, there were once hesitations and fluctuations in thoughts, but the personal values of focusing on career, based on one's own job, pragmatic, hardworking, thinking, and learning have always guided work and study, and truly achieved "what changes is identity, what remains unchanged is the pursuit of value".

\subsection{Understanding the Relationship Between Teaching and Learning in the Transformation from Student to Teacher}

As a student, the central task is to learn knowledge and skills. There is no doubt that I have had the most contact with the faculty during my 11 years of study. At first, I thought that teachers' work was relatively dull and boring. I also complained about the teaching methods of the teachers, felt that the methods and means of the teachers were not advanced enough, and the teaching content was boring and not in-depth enough, etc. When I became a teacher after just know three feet platform is not easy, once some confused at a loss. To prepare for a good class, it usually takes six or seven hours, even more than ten hours. Suddenly, I had a different understanding of the teacher's work, and then I deeply realized what it means to "get something on paper, and finally feel shallow, and absolutely know that I have to practice it".

When I first became a teacher, I couldn't adapt to the sudden change of identity, and I didn't have a deep understanding of the teacher's mission and responsibilities. In addition, I was not familiar with the work at the beginning, and I once mistakenly thought that the significance of teaching was not great, and the emphasis was on scientific research. After a period of exploration, I gradually understand that the greatness of teachers is embodied in the unknown "three feet platform", which is reflected in selfless dedication and persistent persistence. After gradually integrating into the role of teacher, combined with the difficulties faced in practical work, I think about what students want to learn and what teachers should teach. In the teaching work, efforts will be made to do academic innovation consciousness throughout the classroom teaching bit by bit. We understand that the most pragmatic and great cause is to be based on our own duty and focus on practical work. What changes is identity, and what remains unchanged is the pursuit of core values in teaching and learning.

The teacher's duty is to teach and educate people, and teaching is for the sake of not teaching. As a teacher, my values are based on my own duty, think about what students think and teach students what they need. Only by focusing on one's own work and standing on the grassroots level can one day make achievements. In the first transition from a student to a teacher, what changes is the content of work, and what remains unchanged is to focus on the career, based 
on the value pursuit of my own job. Such values guided me to rise to the difficulties when I encountered difficulties, and I successfully completed the first practice of core values in my first position.

\subsection{Strengthening the Role of Management and Education in the Transformation of Teachers to Team Cadres}

It has been less than three months since I got familiar with the teacher's work. In September, I received an order from the higher authorities to be transferred to the deputy captain of the third team of the military basic education team, and started another practice at the grassroots level. As for work transfer, I can gradually understand the organization's intention: to deepen the understanding of grass-roots work, starting from the most basic and fundamental at the grassroots level, in order to lay a solid foundation and go further step by step. In this way, the second transformation began, which also strengthened the pursuit of unchanged core values.

The third cadet team is a third-year undergraduate cadet. After more than two years of military academy life, the cadets are basically used to the military academy life, and they have no initial freshness and enthusiasm. They have no enthusiasm for doing anything and fall into a tired state of mind. Although at the beginning I was full of enthusiasm into the daily life of the three teams, but based on this reality, the daily management of the team inevitably encountered some difficulties. In the face of such a situation, I once doubted whether there was a problem in the management mode, whether it went the old way again and fell into a vicious circle. However, no matter how the environment changes, I have always used "focus on the career, based on own duty" as the guidance of work and study. After several heart-to-heart talks with the representative students, I gradually mastered the ideological dynamics of the students, combined with practical work experience, changed some working methods from the perspective of the students, strengthened the cultivation of the students' values, and strengthened the students' ideals and pursuit. At the same time, timely through the development of a number of values related education activities, gradually opened the direction in the work, and students together. On the other hand, due to my experience as a teacher, I especially strengthened the communication between the team members and the teachers, paid attention to opening up some platforms and opportunities, and strengthened the contact between the students and the teachers.

Under the guidance of focusing on my career and based on own duty, I completed the second transformation. In the second transformation from a teacher to a team leader, I strengthened my determination to work at the grass-roots level. More importantly, I enriched the experience of another kind of grass-roots work and understood how grass-roots management was carried out. This is a way of work different from that of a teacher, Through the transformation, it not only strengthened the life orientation, but also deepened the understanding of the core values, and once again explained the practical guiding role of the core values of soldiers with personal experience.

\subsection{Triple Transformation, Taking Root at the Grassroots Level and Sublimating the Value}

What has changed is identity, and what remains unchanged is the pursuit of core values. In a few months, my role has changed among students, team leader and teacher (as shown in Fig. 
1), but what remained unchanged was my steadfast work based on my own duty and the practice of the core values of contemporary soldiers.

The process of personal growth and progress is not accomplished overnight. It does not reach the height of core values at the beginning, but a process of getting closer to it gradually, that is, our growth is a sublimation process of merging individuality into commonness (Fig. 2). Combined with years of study and work experience and lessons, I gradually understand the personal values, that is, focusing on my career, based on their own duty, practical, willing to work, more thinking, more learning. Such values are the realistic development and practical application of the core values. Compared with the core values, they come down in one continuous line and keep pace with the times. Naturally, the process of practicing values in this way has not reached the height of "being loyal to the party, loving the people, serving the country, dedicating to the mission and advocating honor". However, I have always firmly believed that only "focusing on the cause and based on one's own duty" is the most fundamental and direct way to practice military core values in practical work and study. No matter what role you are, core values are guidelines and guide the way forward.

It is worth noting that we should use a dynamic thinking to understand the essence of values. As Engels said: "All rigid things melted, all fixed things dissipated, everything that was considered to exist forever became something fleeting, and the entire natural world was proved to be moving in eternal flow and circulation (Engels, 1984). The natural world does not exist, but is generated and passed away." Everything changes in motion, and the formation of personal values is dynamic, not a stable state, but the core values of contemporary revolutionary soldiers as we know them today are relatively unchanged. The two are not contradictory. The core value of contemporary revolutionary soldiers is a highly sublimated and summarized value concept, with a sense of universal recognition and strong practical operability. Being loyal to the party, loving the people, serving the country, devoting one's life to mission, and advocating honor is the promotion of the values of all revolutionary soldiers, and it is a common thing.

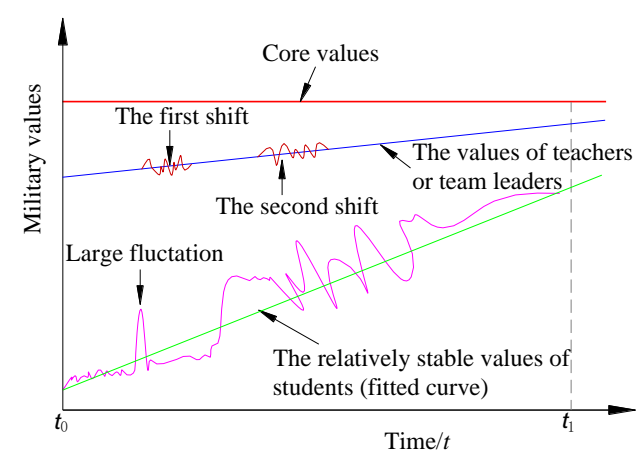

Fig. 2: The Formation and Dynamic Development Process of Values of Teachers (team Leaders) and Students

\section{Cultivating People, Cultivating Morality and Guiding Value Orientation -- the Realistic Direction of the Practice of Core Values}

Based on the current team leader position, combined with the actual work needs, gradually deepened another understanding of the core values of military personnel, that is, to shape the values of training students as a main way of personal practice of core values. Students are in a 
critical period of growth, their understanding of the world is not stable and profound, and their values are still in the process of cultivation and formation. As an elder brother, a senior brother who has also experienced the confused period of students, as a team leader, it is a need of work and a kind of concern from the heart. It has become a realistic problem to take the cultivation of students' values as the focus and direction of personal practice of core values.

After several years of study, now I have a rational understanding of the world, and my values have gradually formed. As for the junior students, they do not have enough rich life experience, and sometimes their understanding of core values is still formalistic. It is difficult to use core values as guidance in their study and life. They unilaterally think that these are "particularly advanced" theories, which have nothing to do with personal growth. In the process of students' growth, the general direction of value development is close to the requirements of the core values, but inevitably there will be some big fluctuations (as shown in Fig. 2). Based on my personal experience of growth and progress, I have carried out various forms of educational activities in the student team, taking the formation of personal values as the main breakthrough. Tell them "What kind of conduct to cultivate and what kind of quality to improve". Strengthening the core values is not an illusory theory, but the guidance of real life and learning. The form of explanation and demonstration as a senior and heart to heart talk education as a team leader are different, but the essence is the same. The purpose is to teach students that the core values are not ivory towers, not castles in the air, but real needs, and the value direction of personal growth and talent.

It is the basic requirement and responsibility for the students to plan their life and future, based on their real study life, and cultivate excellent military quality and professional skills. The duty of the team leader is to guide the students to grow up, create an environment suitable for their life and learning, cultivate and guide the formation of students' values, and integrate the core values into daily life. In the role of team leader, practice the most vivid and pragmatic understanding of core values with practice and dedication, regard dedication to work as the value criterion, and shape the value orientation of students as another way to deepen the understanding and practice of core values. That is to focus on the career, based on one's own duty, what changes is identity, and what remains unchanged is the pursuit of value.

\section{Four Orientations and Dynamic Understanding -- Deepening the Theoretical Study of Core Values}

Combined with above process of changing roles, I have obtained a new theoretical breakthrough in the understanding of core values: "dynamic understanding". Engels has already clearly stated the view that things are changing [14]. In the education of core values, the first problem to be solved and considered is what personal values are and how to unify personal values and core values. Personal values are changing, and noble guidance is needed in the process of forming changes, so the core values of revolutionary soldiers came into being. Now that we understand the plasticity of values, we must learn to use dynamic viewpoints to solve theoretical and practical problems in the process of value learning. Regardless of whether we are students or in different positions, our values change with time, but how to seek a constant and a value orientation that is worthy of being followed in this change has become the key to our discussion today.

Fig. 3 shows the author's understanding of the composition of values. Personal values include self-orientation, environment orientation, ideal orientation and time orientation. There is no 
doubt that self-orientation is your understanding and attitude towards yourself at this stage. Self-orientation is a foundation for the formation of values. What kind of self-orientation determines your enthusiasm for work and study. Of course, this kind of self-orientation is also a prerequisite for the formation of values; Environmental orientation is the environment of your social life in three aspects. This environment includes the different concepts of big environment and small environment. For us, the big environment is the national conditions, military conditions and college conditions (the construction and development of the college's new campus). Such a big environment is the cornerstone of your personal growth, and the small environment is your current working environment and living environment. Under the influence of different environmental factors, personal values will also be deeply affected. Then there is the ideal positioning. The ideal determines your direction. The motive force of all work and study comes from the vision of the ideal. The ideal is not immutable, but also affected by other factors. The combination of the ideal positioning and the core values is a powerful guarantee to solve the problem of values. Time positioning refers to different time periods, each person's other triple positioning is different. Since there are all kinds of changes and differences, do we still have a relatively constant standard of value orientation? Of course, this is the core value of the modern soldier.

Each of us is in such a coordinate, with different self-positioning, environment positioning, ideal positioning and time positioning. The coordinate is also changing with the change of time and constantly. What's important is that we need a common character and the same thing among the differences. The core values solve such a problem. The core values point out the direction for the cultivation and formation of our personality. This relatively stable value concept has been recognized and understood by the vast majority of people and regarded as a common code of conduct. In the voyage of life, there will be strong winds and waves at any time, but our sails must be towards a fixed direction, because the success will never be reached easily. Without firm will and correct direction, we can only waste our time. In the final analysis, it is "taking the core values as the guide, focusing on the career, based on one's own job" as the personal value orientation, I believe that the other side of success must be not far ahead.

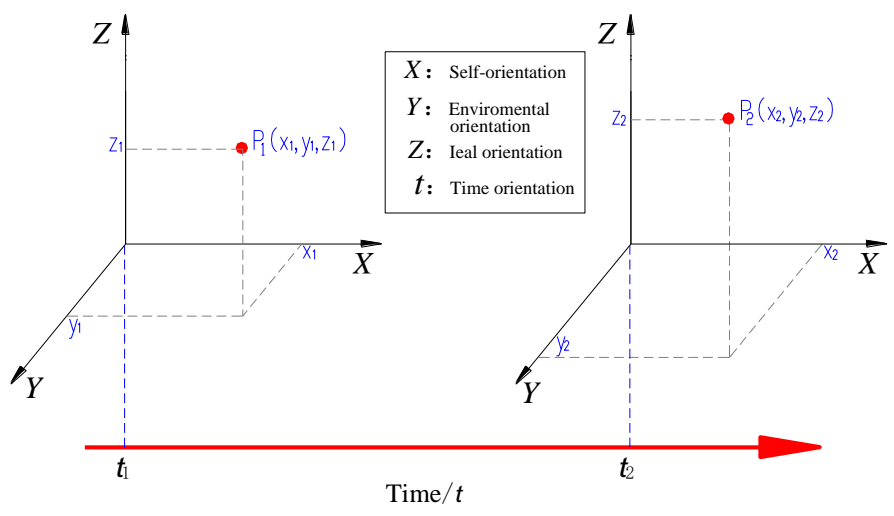

Fig. 3: The Dynamic Model of "four Orientations" Values

\section{Conclusion}

A successful and meaningful life can be defined as "doing the right thing at the right time and place". What is the correct standard? This is a question that needs to be discussed. There is no doubt that the core values of the modern soldier solve this problem.

To practice the core values of the contemporary revolutionary soldiers with practical actions is the realistic demand for talent and the correct understanding of life. To understand the core 
values from a dynamic point of view, focus on the cause, based on their own duties, practice their personal life values in different roles, closely link their personal values with the core values of revolutionary soldiers, and be a contemporary revolutionary soldier with lofty conduct and core values, while being loyal to the party, loving the people, serving the country, dedicating to the mission under the guidance of advocating honor, "focusing on the career and based on one's own duty " is the core values of contemporary soldiers that I have been practicing.

\section{Acknowledgements}

This research was substantially supported by the graduate education and teaching reform research project of Chongqing Education Commission in 2019 (No. yjg193145).

\section{References}

1) Chen, H. J. (2015). "The study of cultivation of the core values about contemporary revolutionary soldiers." Doctoral Dissertation of Hunan Normal University, pp. 1-152

2) Dong, H. L., \& Zhou, L. Y. (2014). "Cultivating the core values of contemporary revolutionary soldiers through "five modernizations"." National Defence (09): 57-58.

3) $\mathrm{Du}, \mathrm{H}$. H. (2014). "Give full play to the guiding role of contemporary military core values." Shaanxi Daily 2014-07-29 (005): 1-2

4) Fang, L. (2016). "On the role and construction of ceremony in the core values education of contemporary revolutionary soldiers." Theoretical Studies on PLA Political Work 17 (05): 84-86.

5) Liu, H. Y., \& Zhang, L. (2015). "On the fit between the cultivation of military core values and traditional culture." Journal of Xi'an University of Political Science 28 (01): 46-48.

6) Liu, Y. (2017). "Research on the characteristics of cultivating the core values of contemporary soldiers." Changjiang series (24): 102-103.

7) $\mathrm{Ma}, \mathrm{P}$. (2014). "On the methods of cultivating the core values of contemporary revolutionary soldiers." Journal of Dalian Institute of education 30 (01): 80-81.

8) Song, X. Y. (2015). "Study on the cultivation of contemporary soldier's core values." Master's Thesis of Jilin University, pp. 1-57.

9) Sui, Z. (2014). "Research on the cultivation of the contemporary revolutionary serviceman's core values." Master's Thesis of China University of Petroleum (East China), pp. 1-52.

10) Tan, F. (2016). "A Research on the content and approaches of cultivating the core values of contemporary revolutionary soldiers". Master's Thesis of Liaoning University of technology, pp. 1-63.

11)Wang, T., \& Zhang, Z. 2018. "Adhere to ideals and beliefs and strive to practice military core values." Knowledge library (06): 213.

12) Wang, Z. (2018). "The Core Values Education of the PLA Today." Doctoral Dissertation of Wuhan University of technology, pp. 1-191.

13) $\mathrm{Xu}, \mathrm{H}$. (2016). "A research on core values cultivation of contemporary soldiers for students of military academies." Master's Thesis of Central China Normal University, pp. 1-56. 
59 | International Journal of Scientific and Management Research 4(6) 51-59

14) Engels F. (1984). "Dialectics of Nature". Yu G. Y Translated, Beijing: People's Publishing House. 